\title{
Complutum
}

ISSN: 1131-6993

\section{Tumbas, materialidad y maternidad en los enterramientos de mujeres con Campaniforme: Dos casos de estudio del valle medio del Tajo}

Rosa Barroso Bermejo ${ }^{1}$; Primitiva Bueno-Ramírez²; Armando González Martín ${ }^{3}$; Rodrigo de Balbín-Behrmann $^{4}$; Juan Manuel Rojas Rodríguez ${ }^{5}$

Resumen. El estudio de dos tumbas campaniformes de la provincia de Toledo se establece como punto de partida para valorar el conjunto de los enterramientos peninsulares de mujeres y la existencia de comportamientos identificativos de sexo. La mujer forma parte de los enterramientos campaniformes y toda la variedad de construcciones, asociaciones y rituales característicos del momento. Los ajuares asociados a ellas muestran heterogeneidad y manifiestan su relevancia social e integración dentro de la sociedad. Es esa socialización la que realmente sitúa los enterramientos femeninos en la misma categoría social que el resto de la población asociada a campaniforme. Que uno de los enterramientos corresponda a una gestante nos permite reflexionar sobre la importancia de la maternidad en el III milenio a.C. y su causalidad en la muerte de mujeres en el pasado.

Palabras clave: Península Ibérica; Toledo; Campaniforme; Calcolítico; enterramiento; mujer.

\section{[en] Tombs, materiality and maternity in the Bell Beaker female burials: Two Case Studies in the middle Tagus valley}

Abstract. Two Bell Beaker tombs in Toledo's province aid to evaluate the women burials from the Iberian Peninsula and the existence of identifiable behaviour based on sex. Women are part of Bell Beaker burials and they appear in all the different constructions, associations and rituals distinctive of this period of time. Grave goods show heterogeneity while displaying her social relevance and integration within their society. This suggests that the women burials remain in the same social status of Bell Beaker communities, regardless of sex. The fact that one of the case studies is a pregnant woman allows us to rethink the importance of maternity in the 3rd millennium B.C. and the casuality of the pregnancy in women death in the past.

Keywords: Iberian Peninsula; province of Toledo; Bell-Beaker; Copper Age; burial; woman.

Sumario: 1. Introducción. 2. Contextos a analizar: Dos casos de estudio de la provincia de Toledo. 3. Tumbas para mujeres. 4. Objetos no solo para mujeres: cerámica, punzones y botones. 5. El cuerpo y su tratamiento. 6. Apuntes finales.

Cómo citar: Barroso Bermejo, R.; Bueno-Ramírez, P.; González Martín, A.; Balbín-Behrmann, R. de; Rojas Rodríguez, J.M. (2018): Tumbas, materialidad y maternidad en los enterramientos de mujeres con Campaniforme: Dos casos de estudio del valle medio del Tajo. Complutum, 29(2): 319-337.

\footnotetext{
Universidad de Alcalá, Facultad de Filosofía y Letras, Departamento de Historia y Filosofía; C/ Colegios 2- 28801. Alcalá de Henares, Madrid.

Correo-e: rosa.barroso@uah.es

2 Universidad de Alcalá, Facultad de Filosofía y Letras, Departamento de Historia y Filosofía; Correo-e: p.bueno@uah.es

3 Universidad Autónoma de Madrid, Laboratorio de Poblaciones del Pasado. Departamento de Biología. Facultad de Ciencias; Correo-e: armando.gonzalez@uam.es

4 Universidad de Alcalá, Facultad de Filosofía y Letras, Departamento de Historia y Filosofía; Correo-e: rodrigo.balbín@uah.es

5 Juan Manuel Rojas arqueología S.L.

Correo-e: jmrojasrodriguez@yahoo.es
} 


\section{Introducción}

En los últimos años son muchos los trabajos centrados en visibilizar las mujeres del registro prehistórico peninsular. Desde distintas perspectivas como la arqueología del cuerpo (Sánchez Romero 2008; Alarcón y Sánchez Romero 2012), la construcción de la identidad (Hernando 2008; Montón-Subías 2010), el estudio de las relaciones de mantenimiento, la infancia (Colomer 2005; González Marcén et al. 2008; Aranda et al. 2009) o en un sentido más amplio la arqueología de género (Montón-Subías 2014), se ha definido el importante papel de la mujer en la sociedad, sin dejar de lado su imprescindible cometido en la supervivencia del grupo. Determinar su posición respecto a los hombres es una primera cuestión pero eso no convierte a las mujeres en un grupo homogéneo, sino que igual que en el caso masculino, las condiciones físicas, habilidades, recursos, y consanguinidad determinan diferencias que nuestro análisis del contexto arqueológico, especialmente funerario, podría llegar a percibir.

En este espacio de trabajo, el Campaniforme, con una mayoritaria documentación funeraria, es un escenario excepcional sobre la identidad y materialidad femenina pues la dicotomía de sexos ha sido una constante en su estudio. En el norte y centro de Europa la posición inclinada hacia el costado derecho e izquierdo de los enterramientos femeninos y masculinos, respectivamente (Salanova 2011), es tradicional identificador de sexo, en ocasiones sin mediar análisis antropológico concluyente. En buena parte, la "masculinidad" dominante en el Campaniforme en Europa es heredada, pues se inserta en el substrato de los grupos de la Cerámica cordada en los que priman los enterramientos individuales asociados a atributos de guerra o caza vinculados a los hombres. Incluso, hasta su propicio marco económico de aceptación con la consolidación del arado o la introducción del caballo (Sherratt 1987) supone connotaciones en la misma línea. Es cierto, sin embargo, que no faltan interpretaciones que otorgan a la mujer la importante labor de trasmisión del Campaniforme, siendo portadoras en sus lazos matrimoniales de sus características cerámicas (Brodie 1997), pero, aun así, su presencia parece desdibujarse en el registro arqueológico. Hay, incluso, cementerios europeos en los que las mujeres están ausentes (Turek 2013).

En la Península Ibérica, la mujer no queda fuera de los enterramientos campaniformes (Liesau et al. 2015) pero los registros también son escasos. Todo ello revaloriza los casos de estudio de la provincia de Toledo, distantes escasos $30 \mathrm{Km}$, que vamos a exponer aquí. El primero, el nicho $3 \mathrm{c}$ de la cueva de Valle de las Higueras procede de un estudio de campo (Bueno et al. 2005). El segundo, la tumba 322 del yacimiento de Las Mayores, aunque no fue estudiado en su momento, confirma las posibilidades que ofrece el material osteológico de los museos (De Miguel 2006: 93) junto a una buena documentación arqueológica. Discutiremos ambos contextos en el conjunto peninsular, centrándonos en los datos sobre tumbas, materiales y reproducción que aportan los enterramientos campaniformes de mujeres.

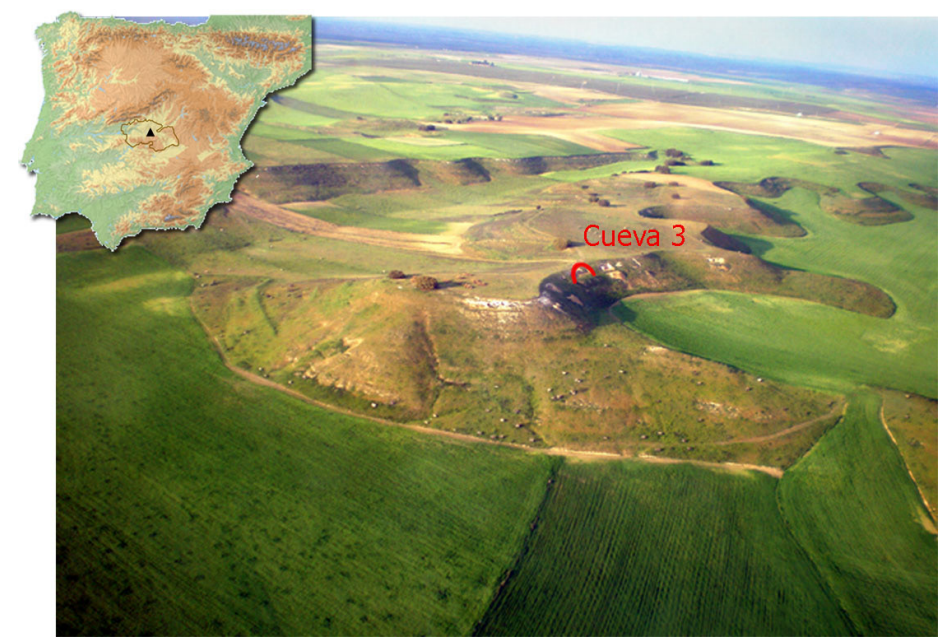

Fig. 1. Localización del yacimiento de Valle de las Higueras, Huecas (Toledo) y vista área del cerro que ocupa la necrópolis con la situación de cueva 3. 


\section{Contextos a analizar: Dos casos de estudio de la provincia de Toledo ${ }^{1}$}

El primer enterramiento femenino documentado procede de la cueva 3 de la necrópolis de Valle de las Higueras (Huecas), Toledo. Se trata de una de las construcciones mixtas, excavadas y construidas que conforman la necrópolis toledana del III milenio a.C. (Bueno et al. 2005, 2008 y 2012) (Fig.1). Se sitúa en el área central del cementerio, en la agrupación de tumbas de su ladera sur, y consta de antecámara, cámara y tres nichos abiertos en sus paredes. En conjunto sirvió para enterrar una treintena de individuos entre los que hay hombres y mujeres, tanto infantiles como adultos. La cerámica campaniforme se reduce a los nichos en los que se reúnen enterramientos dobles y triples. De ellos nos interesa el nicho 3c (Fig. 2), en el lado norte de la cámara central, pues en él se enterró una mujer adulta en decúbito lateral izquierdo, con las piernas flexionadas, su mano derecha muy próxima a la mandíbula y la cabeza orientada hacia el Sureste. A la altura de su cadera se colocó un niño de 7 años $( \pm 2)$, así como restos de un tercer individuo de 3 años $( \pm 1)$, que posiblemente sea un enterramiento secundario incorporado al depósito. De la mujer procede una fecha C-14: Beta 157730: $3810 \pm 40$ BC. Junto a los restos óseos se depositó un ajuar campaniforme liso formado por un vaso, cazuela y cuenco, además de la presencia de cinabrio sobre el conjunto de los restos. Los análisis de residuos realizados en el cuenco revelaron que su último contenido fueron grasas (Bueno et al. 2005: 76).

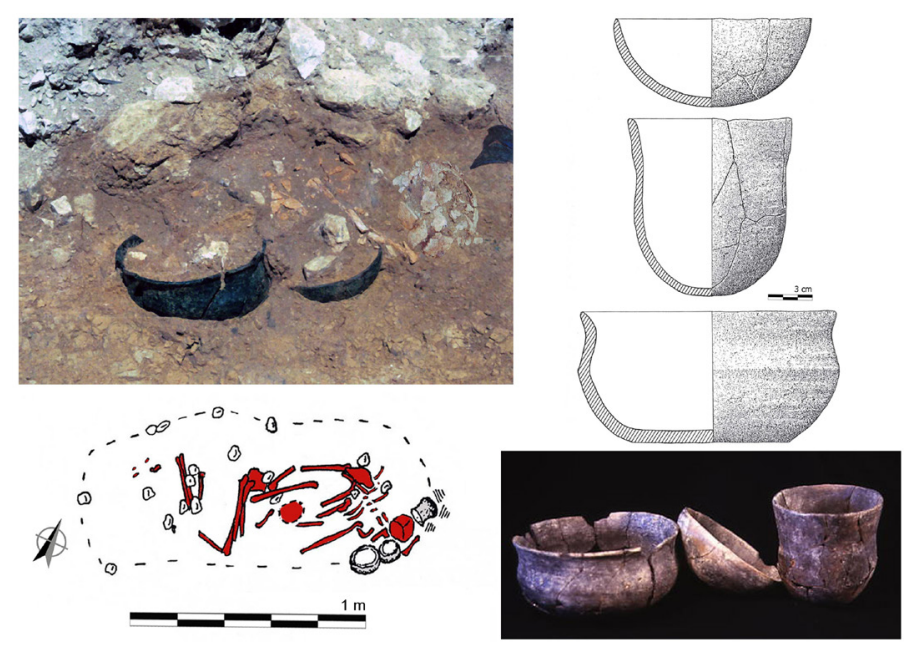

Fig. 2. Fotografía y dibujo del enterramiento del nicho $3 \mathrm{c}$ de cueva 3, Valle de las Higueras (Toledo). A la derecha, dibujo y fotografía del trio campaniforme liso que formaba parte del enterramiento. Fotos R. de Balbín.

No sabemos si hay alguna mujer más en el resto de los nichos, pues no ha sido posible identificar el sexo de los enterrados, pero si en las dos cámaras que conforman la cueva. En la cámara central (3C) se enterraron al menos 10 individuos primarios en posición flexionada sobre dos enlosados de piedra y restos, posiblemente secundarios, de un infantil. De cuatro de ellos se ha podido identificar el sexo siendo al menos dos las mujeres adultas enterradas. En la antecámara (3b) se localizaron los restos de al menos doce enterramientos en posición muy encogida, algunos de ellos secundarios. Pudo determinarse el sexo de tres adultos, dos hombres y una mujer. Los ajuares de ambas cámaras, formados por cerámica lisa, puntas de flecha líticas, punzones de metal y adornos, son colectivos salvo por algunos elementos personales. Este el caso de una de las mujeres de la base de 3C (M-9) que llevaba en el cuello un collar de cuentas de variscita y una concha (Margarita auricularia), a la altura de la mano, además de tener restos de cinabrio en sus huesos. Es el único individuo del conjunto con amplia presencia de caries. De un fragmento de hueso se obtuvo una fecha C14: Beta-205141: 3860 440 BP (Bueno et al. 2005:82).

El segundo contexto de la provincia de Toledo, la tumba LM322, procede del yacimiento de Las Mayores (Numancia de la Sagra) (Fig. 3). El enclave fue excavado en el 2006 y dado 
a conocer en una nota preliminar (Perera et al. 2010). Se trata de un campo de hoyos en el que se localizaron 605 fosas. De ellas una parte acoge enterramientos cuyas cronologías absolutas, a la par que la propia tipología cerámica, campaniforme y Cogotas, determinan su uso al menos durante el III y II milenio a.C. Hasta el momento sabemos que siete estructuras fueron utilizadas como tumbas en un intervalo del 2473-2152 cal BC $^{2}$ delimitando una pequeña necrópolis campaniforme de $150 \mathrm{~m}^{2}$. Al menos
21 individuos fueron enterrados en ella reuniéndose tumbas de hasta 6 individuos y otras en las que prima la individualidad. Seis de la tumbas presentan una tipología similar con planta bicameral separada por un muro que implica una concepción previa del espacio funerario y un comportamiento unívoco de cierre de las tumbas. Frente a la agrupación de la $2^{\mathrm{a}}$ mitad del III milenio a.C., el resto de los enterramientos de la Edad del Bronce aparecen en distintos sectores del yacimiento (Barroso et al. 2018).

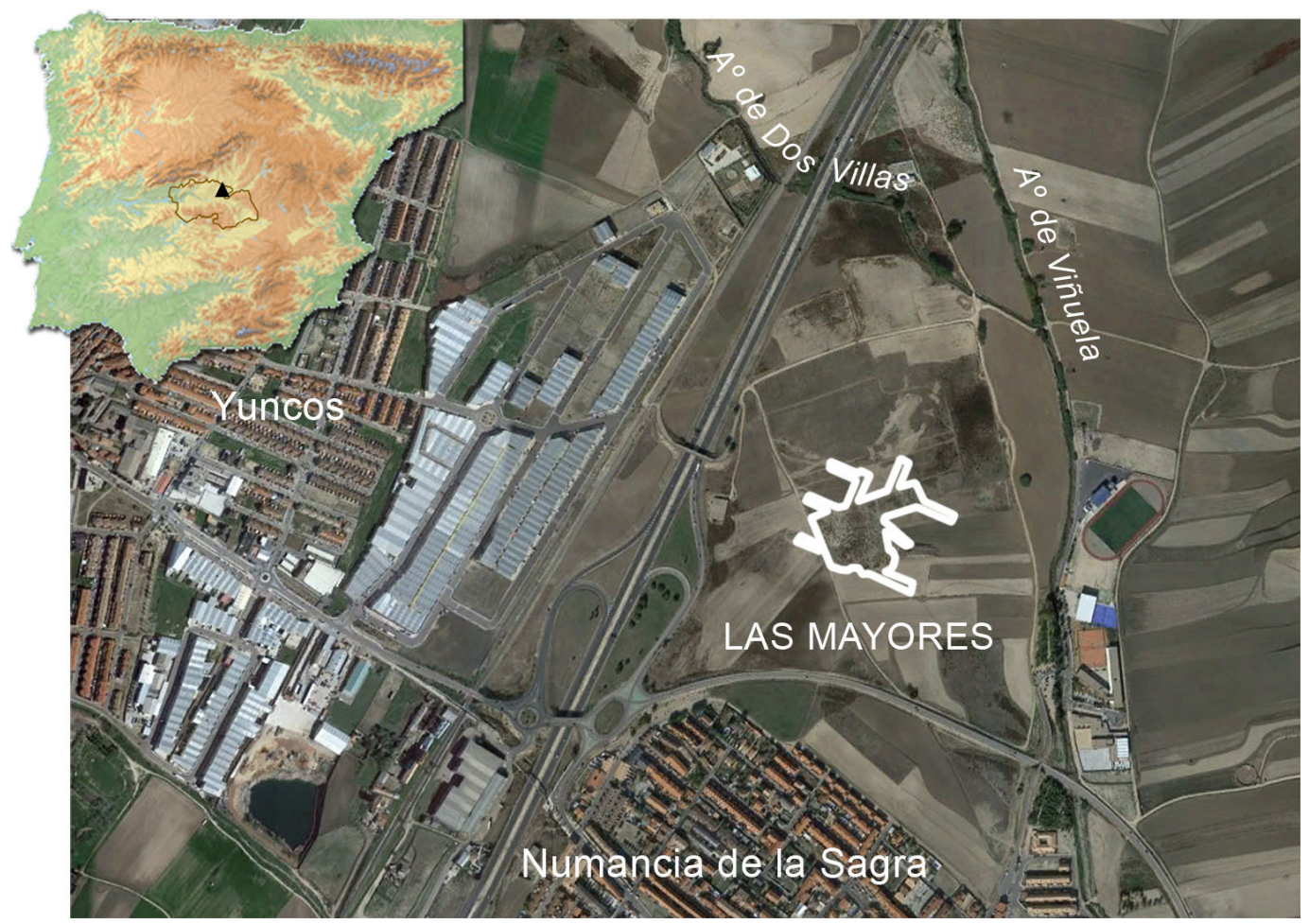

Fig. 3. Localización del yacimiento de Las Mayores, Numancia de la Sagra (Toledo) y vista aérea con el sector abierto en la campaña del 2006.

La tumba que detallamos forma parte de la necrópolis campaniforme (Fig. 4). Se trata de un pequeño hipogeo de planta geminada que consta de cámara y antecámara. Ambas se separan por un muro trasversal de piedra calcárea trabada con barro que cierra de forma vertical la cámara, extendiéndose en talud hacia la antecámara de acceso. En un reducido espacio cameral se depositó el enterramiento de un individuo pegado a la pared noreste de la construcción. Se colocó en decúbito lateral izquierdo, con la cara hacia el sur, piernas flexionadas y con los brazos extendidos hacia el muro. Había restos de colorante rojo, identificado como cinabrio ${ }^{3}$, entre el sedimento y en los huesos de cráneo, torso y extremidades. El estudio antropológico determinó que se tra- taba de una mujer adulta joven de entre 21-24 años con patologías orales en 5 piezas dentales, cuatro de ellas interdentales y un absceso al nivel del primer molar izquierdo. Junto a ella estaban los restos de un perinatal de 3436 semanas de gestación. La documentación gráfica muestra algún movimiento postdeposicional en la pelvis que podría interpretarse dentro de un proceso de desarticulación en espacio no colmatado o su cubrición con un elemento perecedero. A sus pies se depositó un cuenco semiesférico de estilo Ciempozuelos y entre el sedimento que cubría el enterramiento se localizó un punzón de cobre y varias piezas de marfil o hueso. De un fragmento de cúbito de la mujer obtuvimos una fecha C-14: Beta471833: $3870 \pm 30$ BP. 

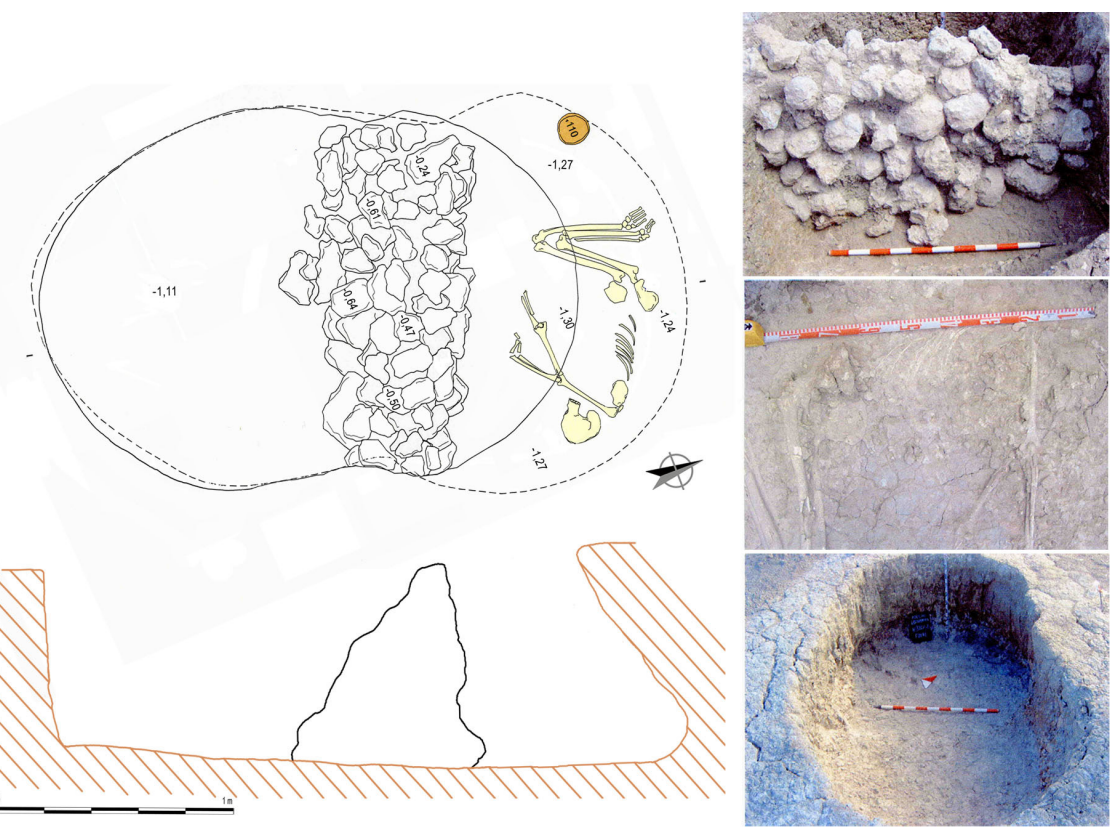

Fig. 4. Planta y sección de la tumba LM322 de Las Mayores, Numancia de la Sagra (Toledo). A la derecha, fotos de LM322 durante el proceso de excavación. La posición exacta de botones y punzón no se recoge pues no se detalla en los dibujos de la excavación.

El cuenco $(16,7 \mathrm{~cm}$ de diámetro de boca y una altura de $6,9 \mathrm{~cm}$ ) tiene superficies alisadas y un ónfalo en la base. Su tamaño, nada fuera de lo habitual, contrasta con el muy alargado y adelgazado punzón biapuntado (14,2 x 0,3 $\mathrm{cm}$ de longitud y grosor máximo). A pesar del estado fragmentario del resto de las piezas se determina la presencia de al menos tres botones con perforación en $\mathrm{V}$ de morfología prismática, semiesférica y cónica. Este último, es un botón con ápice aplanado que se suma a lo discutido en torno a otras piezas madrileñas del mismo tipo. O se trata de una forma originariamente troncocónica (Garrido 2000: 191) o se rompió y siguió usándose (Liesau 2016: 77-78). Esta última opción se adapta mejor a nuestro botón que presenta un brillo en el plano superior muy distinto del proceso de abrasión y pulido del resto la pieza. En todos ellos la base es la parte menos trabajada, luego parece que irían cosidos o adheridos a una superficie, y tienen restos bien visibles de cinabrio, incluso al interior de la perforación. El resto de los fragmentos forman parte de una cuarta pieza, una placa que conserva un reborde lateral, quizás un pequeño peine, si bien su estado de fragmentación impide precisar más (Fig. 5).

Fragmentos cerámicos poco significativos y escasos restos de fauna forman parte de los niveles de colmatación de cámara y antecámara. Esta última, con dos niveles: uno primero formado por una matriz muy semejante al terreno natural y al relleno localizado en la cámara, prácticamente estéril, y un relleno posterior con mayor contenido antrópico y composición arenosa que terminó por colmatar la estructura. Más interesante es un fragmento de borde campaniforme puntillado localizado en el desmonte del muro.

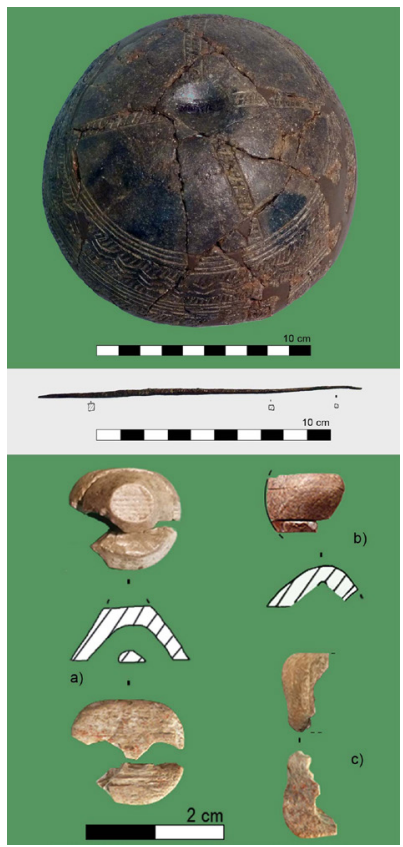

Fig. 5. Cuenco, punzón de cobre y botones (a-c) localizados en LM322 de Las Mayores (Numancia de la Sagra, Toledo). 
Aunque los restos fetales fueron recogidos junto con los de la mujer, sin diferenciarse en campo, su presencia conjunta es una primera cuestión a tener en cuenta. Una segunda cuestión es la edad de muerte estimada, en plenitud reproductiva y su disposición. Tenía las piernas flexionadas pero escasamente inclinadas hacia el torso y los brazos extendidos a diferencia del resto de las tumbas calcolíticas del yacimiento en las que los brazos aparecen flexionados y las manos en la cara o próximas a ella. Es factible pensar que la disposición de los brazos y piernas viniera determinada por el volumen de su abdomen, por tanto consideramos que el registro de campo y el estudio osteológico sugieren que se trataría de una mujer embarazada. El primer registro de este tipo documentado en la Península durante el III milenio a.C.

\section{Tumbas para mujeres:}

Los dos enterramientos seleccionados, en Valle de las Higueras y Las Mayores, son una prueba clara del acceso de la mujer al enterramiento Campaniforme en la misma pauta observada en el resto del Tajo medio (Liesau et al. 2015). Aquí, en plena cuna del Ciempozuelos, los enterramientos femeninos están presentes en todos los yacimientos con registros funerarios de una cierta variedad y extensión, sin faltar en yacimientos emblemáticos como Ciempozuelos (Sampedro y Liesau 1998: 41 y 51) donde se detectó la existencia de 3 mujeres de distinta edad.

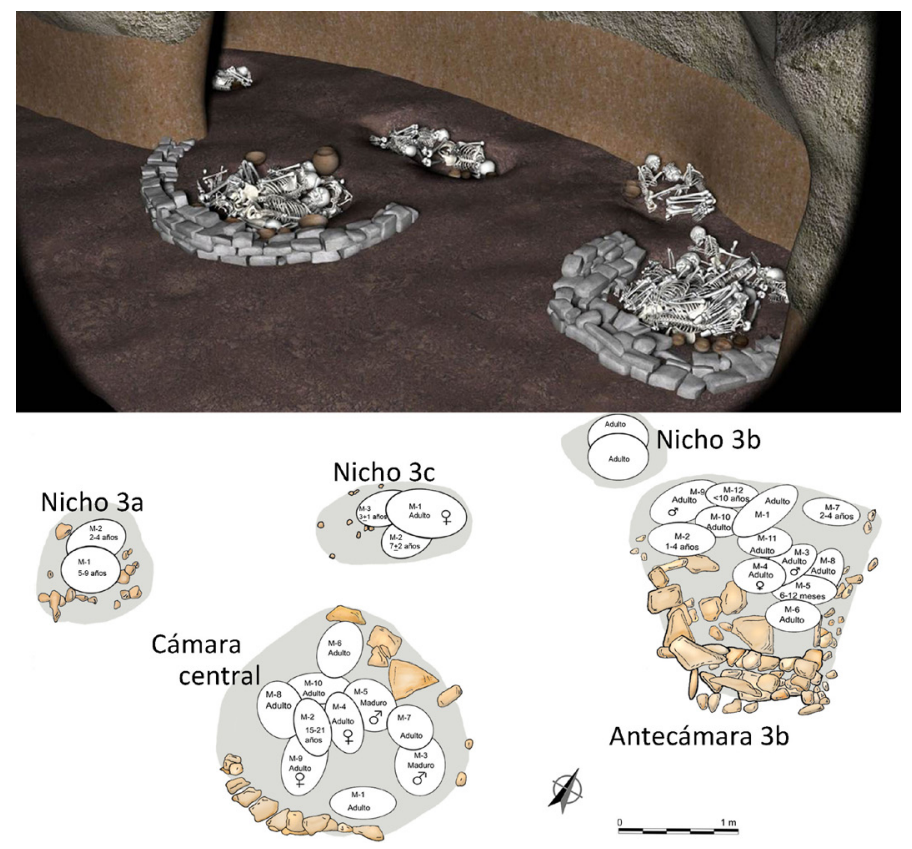

Fig. 6. Recreación de cueva 3, Valle de las Higueras (Toledo) a partir de Bueno et al. 2017: Fig. 4. En la mitad inferior, edad y sexo de los enterrados en las cámaras y nichos de la cueva.

Son muchos los conjuntos osteológicos del Neolítico Final/ Calcolítico peninsular que muestran la presencia de poblaciones naturales con relación equilibrada de mujeres y varones (Mercadal y Agustí, 2003; Antunes-Ferreira 2005; Barandiarán 1978; Linares y Vera 2015). Sin embargo, con Campaniforme se ha señalado un mayor número de enterramientos masculinos aun cuando se insiste en la provisionalidad de los datos y en la gran variabilidad interna dentro de cada yacimiento (Garrido 2000:60; Liesau et al. 2015: 115). Los únicos estudios demográficos disponibles, limitados al tramo medio del Tajo, no avalan diferencias entre sexos sino únicamente una mayor presencia de adultos (Pérez Villa 2015: 77). Hay cuestiones que sin duda condicionan nuestros escasos datos. En primer lugar, la dificultad de identificación antropológica (Rascón 2017). De los 30 enterramientos de la cueva 3 de Valle de las Higueras, entre los que hay adultos y niños, se identifican cuatro mujeres y tres hombres, pero el $77 \%$ de los individuos son de sexo indeterminado (Fig. 6). En segundo lugar, la inserción del campaniforme en los tradicionales sepulcros colectivos que dificulta su individualización. Ambos aspectos determinan una nómina limitada de registros (Tabla.1). 


\begin{tabular}{|c|c|c|c|c|c|c|c|c|c|c|}
\hline Yacimiento & Tipo & $S$ & Edad & $E$ & Posición & Ajuar & $\mathrm{HgS}$ & Fecha (BP) & Cal B.C. & Bibliografía \\
\hline \multirow{3}{*}{$\begin{array}{l}\text { V. Higueras } \\
\text { nicho } 3 \mathrm{c}\end{array}$} & \multirow{3}{*}{$\mathrm{H}$} & $\mathrm{F}$ & adulta & $1^{\circ}$ & lat.izq. & \multirow{3}{*}{ vaso,cazuela y cuenco lisos } & \begin{tabular}{|l|}
$x$ \\
\end{tabular} & Beta-157730: $3810 \pm 40$ & $2456-2137$ & \multirow{3}{*}{ Bueno et al . 2005} \\
\hline & & 1 & 7 a. $( \pm 2)$ & $1^{0}$ & & & $x$ & & & \\
\hline & & 1 & 3 a. $( \pm 1)$ & $2^{\circ}$ & & & & & & \\
\hline \multirow{2}{*}{ LM.322 } & \multirow{2}{*}{$\mathrm{H}$} & $\mathrm{F}$ & 21-24 a. & $1^{0}$ & \multirow{2}{*}{ lat.izq. } & \multirow{2}{*}{ cuenco, punzón, 3 botones } & \multirow{2}{*}{$x$} & Beta-471833: $3870 \pm 30$ & $2465-2211$ & \multirow{2}{*}{ En este trabajo } \\
\hline & & I & $34-36 \mathrm{~m}$. & $1^{\circ}$ & & & & & & \\
\hline C. Yeseras A-2 & \multirow{2}{*}{$\mathrm{H}$} & $\mathrm{F}$ & $20-30$ a. & $1^{0}$ & lat. Izq. & \multirow{2}{*}{3 cuencos campaniformes } & & & & \multirow{2}{*}{ Liesau et al. 2015} \\
\hline A36 El-03- VII & & 1 & 1 ( \pm 1 a. $)$ & $1^{0}$ & & & & Ua $35021: 3525 \pm 40$ & $1956-1743$ & \\
\hline $\begin{array}{c}\text { C. Yeseras A-3 } \\
\text { F-5-I }\end{array}$ & $\mathrm{H}$ & $\mathrm{F}$ & $20-30$ a. & $1^{\circ}$ & lat. dcho & vaso y cuenco campaniforme & & & & Liesau et al . 2015 \\
\hline \multirow{4}{*}{$\begin{array}{c}\text { C. Yeseras A-3 } \\
\text { F-5-II }\end{array}$} & \multirow{4}{*}{ H } & M & $?$ & $2^{\circ}$ & & & & & & \multirow{4}{*}{$\begin{array}{l}\text { Liesau et al . } 2015 \\
\text { Blasco et al. } 2016\end{array}$} \\
\hline & & $M$ & maduro & $2^{\circ}$ & & & & & & \\
\hline & & $\mathrm{F}$ & \pm 40 a. & $1^{\circ}$ & lat. izq? & cazuela camp., vaso, mortero, punzón & & Beta-184837: $3740 \pm 40$ & $2285-2029$ & \\
\hline & & M & $30-40 \mathrm{a}$. & $1^{\circ}$ & & 2 cuencos, vaso campanforme y molino & & & & \\
\hline \multirow{2}{*}{$\begin{array}{l}\text { Humanejos } \\
\text { UE } 1853\end{array}$} & \multirow[b]{2}{*}{$\mathrm{H}$} & $\mathrm{F}$ & \pm 20 a. & $1^{0}$ & lat. dcho & \multirow{2}{*}{$\begin{array}{c}2 \text { punzones } \\
\text { alabarda, puñal, } 2 \text { Palmelas, brazal, cuenco, } \\
\text { cazuela, cuentas y botones marfil }\end{array}$} & & Ua-43525: $3797 \pm 32$ & $2345-2136$ & \multirow{2}{*}{$\begin{array}{l}\text { Blasco et al. 2016; } \\
\text { Liesau et al. } 2015\end{array}$} \\
\hline & & M & $45 \mathrm{a}$. & $1^{0}$ & lat. izq. & & $x$ & Ua-43524: $3917 \pm 33$ & $2482-2295$ & \\
\hline La Vital 10 & $\mathrm{~F}$ & $\mathrm{~F}$ & $20-25 \mathrm{a}$. & $1^{\circ}$ & lat. dcho & vaso campanforme y cuenco liso & & Beta-229791: $3920 \pm 50$ & $2568-2214$ & Garcia Puchol et al. 2011 \\
\hline El Calvari (IV) & C & $\mathrm{F}$ & $25-30 \mathrm{a}$. & 10 & lat. dcho & cuenco liso, 5 botones, frag. vaso & & & & Soriano et al. 2016; Estevez 1966 \\
\hline \multirow{3}{*}{\begin{tabular}{c|} 
La Magdalena \\
UT-4600
\end{tabular}} & \multirow{3}{*}{$\mathrm{H}$} & $\mathrm{F}$ & adulta & $2^{\circ}$ & & Vaso campaniforme, olla y cuenco liso & & & & \multirow{3}{*}{ Heras et al. 2014} \\
\hline & & $\mathrm{F}$ & adulta & 10 & lat. izq. & & & & & \\
\hline & & $\mathrm{F}$ & senil & $1^{\circ}$ & lat. izq. & & & & & \\
\hline \multirow{2}{*}{ La Sima } & \multirow{2}{*}{ D } & $\mathrm{F}$ ? & adulta & $1^{\circ}$ & lat. izq. & 2 vasos, punta de flecha, botón, 2 punzones & & KIA-17999: $3860 \pm 30$ & $2461-2210$ & \multirow{2}{*}{ Rojo et al. 2005} \\
\hline & & $F ?$ & adulta & $1^{0}$ & lat. izq. & 2 vasos y brazal de arquero. Puñal y cazuela? & & KIA-18000: $3862 \pm 28$ & $2462-2211$ & \\
\hline
\end{tabular}

Tabla 1: Enterramientos femeninos asociados a Campaniforme.

Las mujeres disponen de la misma diversidad de tumbas que el resto de los inhumados a nivel constructivo. Se entierran en hipogeos como muestran los casos de Toledo y otros tanto de la comunidad de Madrid (Liesau et al. 2015; Heras et al. 2014), fosas (García Puchol et al. 2011: 85), cuevas (Soriano et al. 2016) o en megalitos como en Castilleja de Guzmán (Lacalle et al. 2000), La Ermita, Galisancho (Benet et al. 1997: 456) o quizás el tholos de La Sima. Aquí dos individuos indeterminados, posiblemente femeninos (Rojo et al. 2005: 172), reactivaron la memoria funeraria de la antigua construcción neolítica. La mujer no queda, tampoco, fuera de las tumbas más complejas y los ajuares singulares (Flores y Garrido 2014). Ahora bien, la sencilla construcción de LM322 parece mostrar un ajuar de más calidad que el nicho $3 \mathrm{c}$ inserto en una compleja construcción como cueva 3 por lo que no siempre se observa una relación clara de tumbas de mayor monumentalidad y mayores ajuares. En cualquier caso, esta diversidad de contenedores funerarios es la propia del Calcolítico (Bueno et al. 2005). Todos ellos muestran, además, la independencia espacial de enterramientos y viviendas, si bien las tumbas se localizan agrupadas, próximas o dentro del mismo ámbito doméstico e incluso reaprovechando estructuras realizadas con otros fines previos.

La individualidad de los enterramientos campaniformes (Blasco et al. 1994: 79) tiene que ser hoy matizada. Hay agrupaciones funerarias, panteones, más que evidentes (Bueno et al. 2005 y 2017; Barroso et al. 2015; Garrido 2014:93) y la mujer forma parte de ellos. Personalizar a diferentes individuos espacial y materialmente no implica su abstracción dentro la comunidad sino un liderazgo sólo comprensible dentro de ella. La mujer del nicho $3 \mathrm{c}$ se inserta en un panteón de uso sucesivo, posiblemente familiar. Proyecta cierta relevancia al segregarse de las acumulaciones amplias de cámara y antecámara y recibir un espacio reservado, pero aun así su cuerpo se deposita junto a dos niños (Bueno et al. 2005).

Tal como muestra LM322, las mujeres pueden ocupar un lugar prioritario dentro de la tumba propiciando su construcción o su reacondicionamiento, como se observa en La Vital (García Puchol et al. 2011). En el nicho 3c, como señalamos anteriormente, la mujer es el centro de la asociación funeraria del contenedor reuniendo en su entorno dos infantiles. Hay también asociaciones de adultas (La Magdalena) y asociaciones de hombre - mujer como reproduce la tumba 1853 de Humanejos. En ella la mujer enterrada, por su situación lateral, se interpreta relegada al varón de cuantioso ajuar metálico y adornos (Liesau et al. 2015: 111). La distancia entre las fechas de ambos, el espacio de apertura que obliga a acomodar el cuerpo menor de la mujer y el carácter acumulativo que podría tener el ajuar o su reorganización tras reabrirse la tumba, son aspectos que deben tenerse en cuenta para valorar la dependencia entre sexos. Quizás la cuestión es por qué este 
hombre de destacada panoplia no dispone de una tumba para él solo.

Puesto que faltan datos de niñas (Tabla 1), únicamente la edad podría condicionar un tratamiento distinto, sin embargo, dada la dificultad de discriminar sexo en los infantiles (González Martín 2008), no se puede asegurar. Hay infantiles que propician estructuras como el tumulo 1 de Aldeagordillo ${ }^{4}$ (Fabián 2006), poseen ofrendas que dejan constancia de un reconocimiento hereditario (Bueno et al. 2005) e incluso se asocian a armas (Linares y Vera 2015: 287). Nada permite certificar, hasta el momento, un comportamiento diferente para las féminas de corta edad.

Por otro lado, todos estos mismos ejemplos reproducen la asociación de depósitos primarios y secundarios tan repetida en los enterramientos campaniformes (Bueno et al. 2005: 78). Las mujeres presentan depósitos primarios y a ellas se asocian enterramientos secundarios o al revés lo que coloca los cuerpos femeninos en la misma dinámica de enterramientos previos y reagrupación que el resto de los individuos.

\section{Objetos no solo para mujeres: cerámica, punzones y botones}

Los elementos materiales que acompañan los enterramientos campaniformes tienen un elevado valor simbólico que identifica al fallecido (Thomas 1991: 39-40). En ellos se observan asociaciones recurrentes que han servido para definir el carácter paneuropeo del Campaniforme, pero también una gran variabilidad difícil de interpretar. Los dos casos de estudio de la provincia de Toledo reúnen las tres grandes categorías de elementos presentes en los ajuares campaniformes: cerámica, metal y adornos.

Aunque la historiografía del Campaniforme ha valorado de forma muy distinta la cerámica, desde destacar la relevancia social de sus producciones (Clarke 1976) hasta el detrimento de los contenedores frente los contenidos (Sherratt 1987), lo cierto es que es un elemento determinante en los ajuares campaniformes (Vander Linden 2006: 159). En varios contextos europeos se destaca su reiterada presencia en los enterramientos femeninos (Shennan 1977: 53) así como la identificación de específicos volúmenes, formas y decoraciones ligadas a las mujeres (Case 1995; Turek 2013: 79).
Detrás de esta asociación, cerámica-mujeres, están argumentos clásicos de base etnográfica que muestran la mayor implicación de las mujeres en la producción alfarera y su trasmisión de madres a hijas (González Ruibal 2005; Rice 1999). Su extrapolación no se reduce al Campaniforme (Garrido 2000: 102-103) sino a otras tantas producciones cerámicas prehistóricas con signos de estandarización como se ha puesto de manifiesto en el estudio de El Argar (Colomer 2005). Las labores de manufactura, aprendizaje, trasmisión y organización de las mujeres se prolongarían, de este modo, en la tumba, identificando su actividad en vida. La trasmisión de habilidades se percibe en pequeñas réplicas, asociadas a enterramientos infantiles, cuyas imperfecciones muestran el aprendizaje en desarrollo de sus creadores (Garrido y Herrero 2015). Esta es una buena forma de plantear que esta actividad productiva no es individual, sino más colectiva de lo que parece. En la obtención de materia prima, su preparación y su elaboración, se comparte instrumental, patrones decorativos, espacios e incluso conocimientos. Por tanto, se implica la participación de muchas personas, de distinta edad y sexo (Larsson 2009).

El trio de recipientes lisos del nicho $3 \mathrm{c}$ o el cuenco Ciempozuelos de LM322 muestran la presencia de cerámica en los enterramientos femeninos. La cerámica es determinante y dominante en los ajuares. Más de la mitad de los enterramientos campaniformes del Tajo tienen cerámica en sus ajuares (Vázquez 2009). Nadie se atrevería a afirmar que todos ellos son de mujeres, de forma que la relevancia de la cerámica en los contextos funerarios se confirma con independencia del sexo determinado para el esqueleto enterrado.

Si admitimos el destacado papel de las féminas en la producción alfarera, en sus distintas facetas, no se trata tanto de ver en la cerámica un elemento propio de mujeres como sugerir su participación directa y activa en el escenario funerario cada vez que una mujer, hombre o niño fallecen. Si admitimos que la producción no es una expresión individual sino integrada en la colectividad, veremos en los ajuares una aportación de esa comunidad.

Hasta el momento no se observa una morfología ni un tamaño específico de cerámica que pueda asociarse a mujeres. Hay vasos, cazuelas y cuencos, incluso en tríos regulares como en el nicho 3c. Estos y el cuenco de LM322 están dentro de los estándares (Garrido 2000: 
94) destacando además que se trata de piezas lisas y decoradas respectivamente.

Precisamente esto nos introduce en otra cuestión diferente. La valía de unas piezas sobre otras. Por ejemplo, la prioridad que otorgamos a los vasos, como recipiente más significativo o el valor de las piezas decoradas que implican un laborioso trabajo ornamental e incluso una asociación de motivos explícita y conocida (Garrido 2000). No parece que tampoco aquí pueda advertirse un comportamiento ligado al sexo. Las variedades son amplias. Frente a piezas de buena calidad y sin aparente uso, expresamente realizados para la ocasión (Garrido 2000: 35), hay ajuares como los de LM322 y en general todas las tumbas de Las Mayores, cuya cocción es de tan mala calidad que aparentan improvisación a pesar de ser piezas decoradas. No faltan tampoco ejemplos que combinan piezas lisas y decoradas (Yeseras A-3 covacha 2) o piezas semiesféricas lisas como la de la mujer de El Calvari (Estévez 1966) que sólo se identifican como ajuar campaniforme por su asociación a elementos reiterados, en este caso botones. Quizás uno de los mejores ejemplos de este tipo lo tenemos en la construcción del recinto ceremonial portugués de Bela Vista 5, motivado ni más ni menos que por la sepultura de una mujer asociada a cerámicas, entre ellas una cazuela lisa, punzón y una punta Palmela. El campaniforme no se prodiga en contextos funerarios del Alentejo donde predominan más los elementos anexos, metalurgia, junto a cerámicas propias de la zona (Valera 2014), distinguiendo también personajes femeninos (Fig. 7).

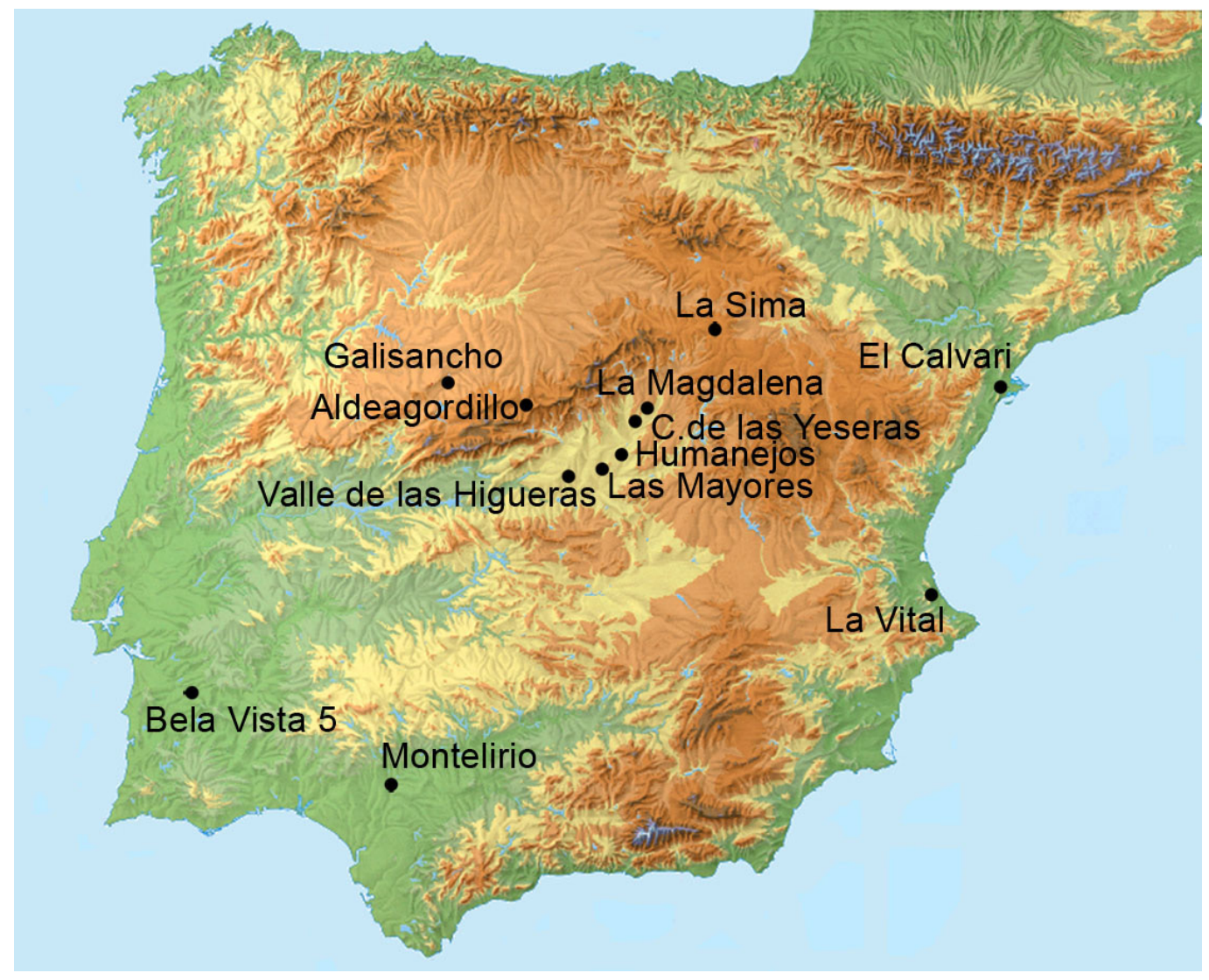

Fig. 7. Principales yacimientos mencionados en el texto.

Es evidente que hay parámetros muy variados en la elección de la cerámica "adecuada", incluso dentro de los propios enterramientos femeninos, y que la calidad no es un requisito fundamental. Todo ello hace pensar que además de la simbología y los aspectos sociales hay también cuestiones funcionales que hay que valorar. No hay que dejar de lado que una producción cerámica elaborada, como es la campaniforme, exige una organización y en el caso de la producción funeraria una previsión ante el imprevisto de la muerte que quizás no 
siempre podría cumplirse, como acertadamente se ha señalado (Liesau et al. 2015: 121). La producción campaniforme exige material, espacio, medios y un tiempo de entre dos semanas y un mes para su fabricación, además de que los meses cálidos serían más proclives que el resto del año (Carvalho-Amaro 2013: 205). Otra cuestión sustancial es la presentación y consumo de alimentos procesados que podrían significar estos recipientes, tal como han revelado algunos análisis de contenidos (Bueno et al. 2005: 76; Guerra 2006; Bueno et al. 2016). Son pocos los datos para contrastar entre enterramientos pero se ha planteado que el sepelio podría ir acompañado de banquetes y ceremonias fúnebres (Rojo et al. 2008). En este sentido, la tumba 10 de La Vital muestra un complejo depósito de fauna y recipientes interpretado como alguna práctica ceremonial en torno al enterramiento de la mujer (García Puchol et al. 2011: 92). Tampoco ellas están fuera de estas prácticas comunitarias.

Los punzones, presentes en los ajuares campaniformes, han sido tradicionalmente relacionados con mujeres (Clarke 1970: 235). La asociación punzón-enterramiento femenino en nuestra Península tiene significativa cuantía en El Argar y aun así permite interpretaciones diferentes. Para algunos autores son considerados elementos que simbolizan la identidad relacional de las mujeres al margen de su clase social (Montón-Subías 2007), mientras otros conectan la variabilidad de tamaño y manufactura de las piezas con la condición social del enterrado, independientemente de su sexo (Cámara y Molina 2009).

A diferencia de la cerámica, en los punzones no es su producción, la metalúrgica, la que se asocia a las mujeres sino su uso. Se vinculan con las diversas prácticas de mantenimiento que ellas realizarían como la manufactura de textiles, el trabajo de pieles, la madera (Montón-Subías 2010: 128) o la decoración de cerámica, siendo instrumentos multifuncionales (Liesau et al. 2015: 119). Hay piezas enmangadas, incluso en contexto funerario (Lomba et al. 2009: 153), pero esto no quiere decir que todas lo fueran, pudiendo hacer también la función de alfileres de telas y el pelo igual que símiles en madera que no nos habrían llegado.
Los punzones aparecen en contextos domésticos y funerarios en proporciones semejantes (Labaune 2013: Fig. 6). Se ha destacado una tipología funeraria de piezas largas y sin uso previo (Montón-Subías 2007: 256; Blasco et al. 2016: 31), sin embargo hay tipos muy distintos lo que sugiere que no todos sirvieron para lo mismo o simbolizaran lo mismo en la tumba, sin olvidar que también aparecen en tumbas masculinas. La pieza de LM322 es especialmente larga y apuntada pero no hay más que fijarse en las piezas localizadas en los yacimientos madrileños (Blasco et al. 2016) o el conjunto de cueva 3 para ver su variabilidad de tamaño, morfología y metal acumulado, sin que se observe miniaturización relacionada con la edad. Recordemos que en cueva 3 la mujer enterrada en el nicho $3 \mathrm{c}$ junto a los niños y un trio campaniforme carece de metal mientras las mujeres y hombres enterrados en la cámara y antecámara del mismo hipogeo, sin asociar a cerámica campaniforme, disponen entre sus ajuares colectivos de 5 punzones y una aguja, esta con su ojiva rota (Fig. 8). Parece traslucirse algo más que diferencias de sexo.

No sólo la asociación a una aguja de cueva 3 es significativa, sino que resulta difícil abstraerse de la relación entre punzones y textiles desde el momento que en Europa central se señaló la importancia, durante el Campaniforme, de los tejidos de lana inspirados en los motivos geométricos de las telas, a la vez que se asiste a la sustitución de botones por alfileres (Sherratt 1987: 89). No hay prueba arqueológica peninsular de esta propuesta más que una destacada cabaña ovicaprina sobre la bovina, en buena parte de los conjuntos calcolíticos (Liesau 2017), sin embargo, hasta la asociación de botones y punzón de la tumba LM322 parece sugerirla. Recientemente, un contexto peninsular excepcional, el monumento de Montelirio, permite recapacitar sobre la importancia de la vestimenta, no sólo de lana. En él se enterró a 20 individuos, buena parte de ellos mujeres, que además de un rico ajuar colectivo portaban indumentarias personales reveladoras de su alta condición social (García Sanjuán et al. 2016: 543). 

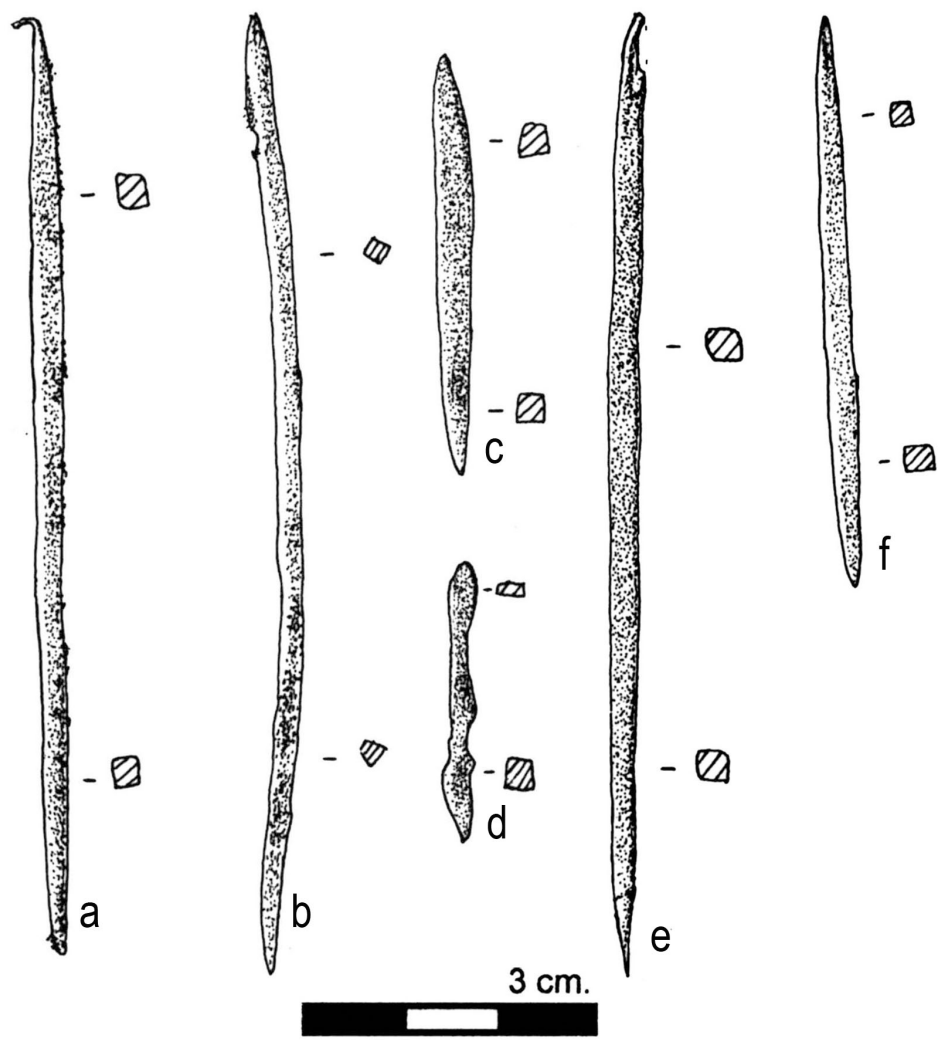

Fig. 8. Punzones y aguja de la cueva 3 de Valle de las Higueras, Huecas (Toledo): a-d: Cámara central 3c; e-f: antecámara $3 b$.

La asociación de individuos femeninos y botones es también bastante reiterada en contextos europeos (Vergnaud 2013: 57), en ocasiones en relación a la mortaja que envuelve al cuerpo al ser enterrado (Makarowicz 2015). En la Península, este tipo de elementos se considera mucho más usual en tumbas masculinas campaniformes (Liesau 2016: 81), sin embargo son varios los ejemplos de tumbas femeninas calcolíticas asociadas a botones de marfil (Soriano et al. 2016; Heras et al. 2014; Zilhao 2016: 382) sin la cerámica característica o con ella, como prueba LM322. La tumba reúne tres piezas de morfología diferente que conviven posiblemente sobre la misma prenda textil cuestionando pensar en diferencias cronológicas a partir de su tipología. Los análisis realizados en botones madrileños confirman su elaboración en marfil de elefante fósil, africano y diente de cachalote planteando su llegada a la Meseta dentro de redes de intercambio con el sur y suroeste peninsular (Liesau et al. 2016), si bien desconocemos los talleres de procedencia. Estas mismas transacciones incluirían cinabrio, las conchas marinas o la variscita presente en cueva 3 (Bueno et al. 2005). En LM322 uno del botones está fracturado por su uso lo que plantea que sean adornos cosidos a una prenda usada, asidua u ocasionalmente, por la fallecida, quizás como visible identificación. Del mismo modo el collar que porta la mujer de la cámara $3 \mathrm{c}$ muestra claras huellas de uso en los orificios de las cuentas de variscita. Si estos adornos sirven para distinguir unos enterramientos de otros, también las personas que los portaron en vida debieron hacerse notar. Su fabricación o adquisición no responde a un exclusivo uso funerario.

Puesto que los botones de LM322 se localizaron entre los restos óseos de su cuerpo, proponemos que pudieran formar parte de su atuendo. El resto de los elementos del ajuar comentados no tienen un orden regular sino que éste viene condicionado por el espacio funerario y la colocación de los enterramientos femeninos. La cerámica se dispone alrededor de la cabeza, en los brazos o a sus pies. En el nicho $3 \mathrm{c}$, el vaso apareció tumbado, quizás caí- 
do, aunque se puso barro ajustando las piezas cerámicas. En la covacha 2 del Área funeraria 2 de Yeseras dos cuencos superpuestos se colocan entre los brazos de la mujer mientras otro más se colocó boca abajo cubriendo los restos del infantil que tenía a sus pies, antes de ser colmatada la tumba (Gómez et al. 2011: 115).

\section{El cuerpo y su tratamiento}

La posición dada al cuerpo femenino en su depósito tampoco aporta particularidad en cuando que se repiten las posiciones flexionadas en decúbito lateral. Se reiteran las inclinaciones hacia el lado izquierdo que muestran las mujeres enterradas en el nicho 3c y LM322 o varias tumbas de Yeseras (Liesau et al. 2015: Tab 1), pero este comportamiento se observa en otros tantos enterramientos masculinos (Garrido 2000: 61; García Puchol et al. 2011). Hasta el momento no puede aquilatarse una práctica fija en la disposición del cuerpo, a diferencia de los contextos centroeuropeos, ni coincidimos en ver aquí un precedente claro de la pauta argárica (Lull et al. 2016: 43).

A pesar de su voluminoso cuerpo, la chica de LM322 mantiene la misma postura anatómica en decúbito lateral izquierdo que el resto de los enterramientos primarios de la necrópolis siendo diferente la posición de las manos que aquí se extienden sobre su abdomen. Su enterramiento individual podría significar un interés expreso por la preservación de la deposición, aunque es cierto que la tumba ha pasado por la misma temporalidad que el resto trascurriendo un tiempo difícil de determinar entre la deposición, cierre y colmatación de la estructura. El único signo de acomodo diferencial de un enterramiento femenino se observa en una tumba del Área funeraria 2 de Yeseras en el que la mujer presentaba la cabeza sobre una capa de sedimento que la sobreelevada por encima del resto del cuerpo (Gómez et al. 2011: 115).

Tras la colocación del cuerpo y el ajuar, son muchos los enterramientos sobre los que se esparce cinabrio. Los análisis del colorante rojo que cubre los huesos de LM322 y el nicho y cámara de cueva 3 muestran su uso también en los enterramientos femeninos con o sin ajuares campaniformes y otros tantos ejemplos tenemos en Madrid (Liesau y Blasco 2012; Liesau 2016). Tres cuestiones son destacables al respecto. La primera es la procedencia del cinabrio que revierte, nuevamente, en redes su- prarregionales. En el caso de los enterramientos de Toledo se localiza al menos a $150 \mathrm{Km}$ de distancia. La segunda, la dificultad de reconstruir la vía de "coloración" pues son varios los procedimientos posibles (Delibes 2000; Liesau y Blasco 2012; Bueno et al. e.p.). Es decir, si el cinabrio se esparce por encima del cuerpo con prendas de vestir incluidas, si se esparce cuando el cuerpo se ha desarticulado, sobre los huesos o si las prendas han sido previamente elaboradas con tintes de cinabrio y, en cualquiera de los supuestos, tener en cuenta el efecto tóxico del sulfuro de mercurio (Emslie et al. 2015). Otra cuestión distinta es si lo que se pretende es preservar, decorar o ambas cosas.

Los casos de Toledo muestran cinabrio sobre los huesos, sobre el sedimento y los restos materiales. Los botones de LM322 conservan rojo más evidente en su parte inferior y la perforación. Dado que la idea de atuendos elaborados con teñidos de cinabrio no se sustenta (López Padilla et al. 2012: 285) hemos de pensar que el cinabrio se extiende por la vestimenta alcanzando los botones, especialmente los hilos con los que se cosen, y se esparce por el enterramiento. Sin duda su rojo brillante, frente al blanco de los botones y posiblemente las telas, convierte la tumba en un escenario de exhibición. Al igual que la cerámica y otros elementos de ajuar, el cinabrio tiene un uso diferencial entre los enterrados, sin excluir a las mujeres. Incluso, en El Argar son mayoría los enterramientos femeninos hasta el punto de considerarse un elemento de "feminidad" en las tumbas masculinas (López Padilla et al. 2012: 289). El proceso de obtención del mineral, su depurado, acumulación y uso (Bueno et. al. e.p.) implicaría, nuevamente, personas de sexos muy diversos.

Tanto el nicho 3c como LM322 traen a colación la importancia de la maternidad en las comunidades prehistóricas. La primera por la repetida asociación de enterramientos de mujeres con niños de corta edad, en este caso incorporados a la misma tumba tras la muerte, quizás de la madre y la segunda por ser la de una gestante. Ambos ejemplos nos recuerdan la importancia de la reproducción social del grupo y las prácticas de socialización. La maternidad no debe entenderse, por tanto, solo como el hecho biológico reproductivo, ni termina en el momento del nacimiento con recién nacidos incapaces de valerse por sí mismos (Sánchez Romero 2006). Hay toda una labor maternal decisiva para el éxito del grupo. 
En sociedades productoras aparentemente sin grandes problemas de hambruna, como debieron ser las calcolíticas, es factible pensar que la fertilidad de las mujeres se traduce en un número elevado de embarazos y partos (De Miguel 2006: 101) de los que queda escasa huella en el registro arqueológico. La tumba LM322 se une a las contadas inhumaciones de gestantes conocidas en contextos prehistóricos europeos Pleistocenos (Vacca et al. 2012; Nava et al. 2017: 1) y Holocenos (Lieverse et al. 2015). Un ejemplo interesante procede de la mujer localizada en una de las cámaras del cairn neolítico de La Hoguette (Calvados, Francia), cuyo vientre justifica la curvatura de su espalda y la posición retrasada de sus piernas a diferencia del resto de los enterrados (Caillaud y Lagnel 1972: Fig. 7).

Son tan pocas las ocasiones en las que conocemos la causa de la muerte que, ante un registro singular como LM322, es tentador pensar en una complicación materna, aunque sólo podamos especular. El parto fue en el pasado una de las principales causas de mortalidad femenina y la joven está dentro del grupo de edad proclive a esta afección. Sin embargo, a diferencia de la tumba neolítica de Lokomotiv (Lieverse et al. 2015) o el enterramiento argárico de Cerro de las Viñas (Malgosa et al. 2004) con el feto en posición trasversa, no podemos proponer un caso de distocia en Las Mayores. No hay forma de conocer las condiciones de reproducción de una mujer del III milenio, ni si eran mejores para aquellas de mayor consideración social, pero en todo caso pueden calificarse de difíciles. Debieron ser múltiples los riesgos de enfermedades, infecciones y hemorragias que pondrían a prueba la salud de la madre llegando a causar su muerte y la del recién nacido (Willis y Osenham 2013), sin embargo en LM322 solo tenemos conocimiento de una mala salud oral de la joven. Es más, se ha propuesto una mejor condición de vida y alimentación de la población distinguida con campaniforme respecto al resto (Liesau et al. 2015 y Gómez et al. 2011:130).

Un ejemplo más de gestante se ha sumado en los últimos años en la Península con la reinterpretación de la tumba doble de Los Tolmos de Caracena como un individuo con el feto aún en el útero (Esparza et al. 2012: 293). Los autores utilizan el caso para justificar el acceso a la tumba del único menor de 6 meses señalando que la práctica inhumatoria se implantaría a partir de esa edad en la Edad del Bronce de la
Meseta. En el mismo sentido, los perinatales escasean durante la Edad del Cobre (Aliaga et al. 2015) aun cuando la mortalidad de niños en los 6 primeros meses de vida debió ser muy elevada. En Centroeuropa tal reducción ha llevado a sugerir enterramientos alternativos por su no aceptación como miembros de hecho de su comunidad (Turek 2013:76). En las Mayores no se trata del único neonato localizado en el yacimiento (Barroso et al. 2018) pero sí en la necrópolis campaniforme. En este caso su factor de inclusión sería no haber nacido aun, formando parte del cuerpo de la madre.

\section{Apuntes finales}

El contexto funerario campaniforme viene marcado tradicionalmente por una dicotomía entre hombres y mujeres ligada en buena parte al modelo funerario popularizado de individuos masculinos asociados a armas. Sin embargo, la mujer no queda fuera de la tumba Campaniforme y los casos recogidos en el trabajo lo subrayan. La dificultad de identificación del sexo de los enterrados determina una muestra reducida que nos sitúa aún lejos de aportar una estadística significativa sobre el acceso de la población al enterramiento. Al menos, es indicativo que la mujer está presente en la diversidad de construcciones funerarias características del momento y forma parte de depósitos individuales y colectivos, primarios y secundarios. No hay una sepultura estándar sino la misma heterogeneidad del resto de los enterramientos.

El excesivo protagonismo dado a los enterramientos individuales aparenta, nuevamente, una situación de desventaja para las mujeres que encontramos en frecuente asociación a otros individuos, muchos de ellos infantiles. Sin embargo, los hallazgos de los últimos años muestran mujeres en tumbas individuales y un predomino de los enterramientos colectivos que involucran a mujeres, hombres y niños con campaniforme (Bueno et al. 2017). Si individualidad es símil de liderazgo también ellas debieron tenerlo, pero es más importante destacar las reiteradas asociaciones funerarias. En ellas la mujer se sitúa fuera de todo aislamiento social proporcionándoles identidad como parte importante de la comunidad. La propia maternidad que refleja el excepcional registro de LM322 sería algo a lo que una mujer difícilmente podría enfrentarse sola. 
En los ajuares asociados a las mujeres está presente la cerámica campaniforme, lisa o decorada, el metal y los elementos de adorno. Las armas, mayoritariamente asociadas a hombres (Lemercier 2011) también tienen espacio en los ajuares de ellas (Liesau et al. 2015; Blasco et al. 2016; Palomino et al. 2006), de forma que no podemos hablar de un ajuar tipo. La realidad muestra mucha variabilidad y la necesidad de adoptar un concepto de género abierto, construido socialmente. La cerámica que determina la tumba como Campaniforme, tanto para hombres como para mujeres, focaliza su producción en ellas, mientras que los punzones que las identifican a ellas pueden haber sido fabricados por los hombres. Como hemos visto, la mayor parte de los elementos implican a hombres y mujeres si nos fijamos en su obtención, producción, elaboración final y uso. Es evidente que además de la determinación biológica del sexo, hay género en cuanto una construcción social dinámica, en continua trasformación y renegociación (Sørensen 2000) dentro de la tumba campaniforme. Masculinidad y feminidad conviven en muchos de los ajuares asociados a hombres y mujeres.

Muerte y vida no deben disociarse estrictamente. Hay rasgos de vida que sin duda se trasladan a la tumba pero también ésta nos alerta de la vida de los enterrados. En este sentido, es visible una distinción de aquellos individuos que singulariza el campaniforme. Los ajuares no vienen determinados por el sexo del enterrado, pero construyen una categoría diferente de hombres y mujeres a los que se asocian, lo que propone una responsabilidad diferente para ellos. La reunión y previsión de elemen- tos de procedencias y cadenas de fabricación diversas, que muestra la tumba campaniforme, supone un acceso diferencial a determinados recursos y por lo tanto una implicación diferente en su proceso de elaboración, obtención y demanda. Las mujeres asociadas a Campaniforme no debieron están tan imbricadas en la producción básica como en la más ocasional de los elementos seleccionados para la tumba. Disponer de estas piezas, controlar los tiempos de su realización y regular la trasmisión de su proceso de elaboración y patrones decorativos no debió estar al alcance de todos. Pudieron regular y beneficiarse, por ejemplo, de una producción textil restringida cuyo tejido, color o adornos distinguiera visiblemente a sus portadoras. Confirmar esta diferente condición social no sólo con elementos materiales sino también con datos osteológicos exige de un registro más amplio y de mayor calidad imprescindible, además, para superar los sesgos tradicionales (Higuero 2015) con los que seguimos abordando los contextos funerarios campaniformes.

\section{Agradecimientos}

El trabajo ha sido realizado dentro de los proyectos CCGC2017-HUM/020 de la UAH y 12122945/2017 JCCM. Armando González Martín, Manuel Campo y Marcos Saez (UAM-LAPP) se encargaron del estudio del material antropológico de la provincia de Toledo. En el acceso a los fondos del Museo de Santa Cruz, Toledo, siempre contamos con las facilidades de su director y técnicos.

\section{Notas}

1. El estudio antropológico ha sido realizado en el Laboratorio de Poblaciones del Pasado de la Universidad Autónoma de Madrid, siguiendo el protocolo y la metodología ya expuesta en trabajos recientes (Díaz del Rio et al. 2017).

2. Todas las calibraciones (Tabla 1) han sido realizadas con OxCal 4.3; IntCal13 atmospheric curve.

3. La identificación mineral de la muestra de colorante fue realizada por el Dr. Odriozola en la Universidad de Sevilla mediante difracción de rayos X.

4. Uno de ellos podría ser femenino (Fabián 2006: 437).

\section{Bibliografía}

Alarcón, E.; Sánchez Romero, M. (2012): Mujeres e identidad: el cuerpo y su contribución a la construcción de identidades en el mundo argárico. Arqueología funeraria desde una perspectiva de género. Universidad Autónoma de Madrid, Madrid: 55-78. 
Aliaga, R.; Liesau, C.; Ríos, P.; Blasco, C.; Galindo, L. (2015): Infant Burials during the Copper and Bronze Ages in the Iberian Jarama River Valley: A Preliminary Study. Children, Spaces and Identity (M. Sánchez Romero, E. Alarcón, G. Aranda, eds.), Oxbow books, Oxford: 243-261.

Antunes-Ferreira, N. (2005): Paleobiología de grupos populaciones do Neolítico Final/Calcolítico do Poço Velho (Cascais). Trabalhos de arqueología 40. Instituto Português de Arqueologia, Lisboa.

Aranda, G.; Montón-Subías, S.; Sanchez Romero, M.; Alarcón, E. (2009): Death and everyday life: The Argaric societies from Southeast Iberia. Journal of Social Archaeology, 9(2): 139-162. https://doi. org/10.1177/1469605309104134

Barandiarán, I. (1978): El yacimiento eneolítico de la Atalayuela en Agoncillo. (Logroño). Príncipe de Viana, 148-149: 381-422.

Barroso, R.; Bueno, P.; Balbín, R.; González, A.; Rojas, J.M. (2018): Inhumaciones en urna cerámica de la Edad del bronce en la cuenca media y alta del Tajo: una perspectiva comparativa. Spal, 27. 1: 27-30. http://dx.doi.org/10.12795/spal.2018i27.01

Barroso, R.; Bueno, P.; Vázquez, A.; González, A.; Peña, L. (2015): Enterramientos individuales y enterramientos colectivos en necrópolis del megalitismo avanzado del interior: la cueva 9 de Valle de las Higueras. Death as Archaeology of Transition: Thoughts and Materials, BAR International Series 2708: 165-176.

Benet, N.; Pérez, R.; Santonja, M. (1997): Evidencias campaniformes en el valle medio del Tormes. II Congreso de Arqueología peninsular, Zamora: 449-470.

Blasco, C.; Montero, I.; Flores, R. (2016): Bell Beaker funerary copper objects from the center of the Iberian Peninsula in the context of the Atlantic connections. Analysis of the Economic Supporting the Social Supremacy the Beaker Groups (E. Guerra; C. Liesau eds), Proceedings of the XVII UISPP World Congress, Burgos, Archaeopress publishing LTD: 19-35

Blasco, C.; Sánchez Capilla, M.L.; Calle, J. (1994): El mundo funerario. El Horizonte campaniforme de la región de Madrid en el centenario de Ciempozuelos (C. Blasco, ed.), Patrimonio arqueológico del Bajo Manzanares/2, Universidad Autónoma de Madrid, Madrid: 75-99.

Brodie, N (1997): New perspectives on the Bell-Beaker culture. Oxford Journal of Archaeology, 16 (3): 297-314.

Bueno, P.; Barroso, R.; de Balbín, R. (2005): Ritual campaniforme, ritual colectivo: la necrópolis de cuevas artificiales del Valle de las Higueras, Huecas, Toledo. Trabajos de Prehistoria, 62, 2: 67-90,

Bueno, P.; Barroso, R.; de Balbín, R. (2008): Campaniforme en las construcciones hipogeas del megalitismo reciente al interior de la Península Ibérica. Veleia, 24-25: 771-790

Bueno, P.; Barroso, R.; de Balbín, R. (2012): 5000 años atrás. Primeros agricultores y metalúrgicos del valle de Huecas (Huecas, Toledo). Castilla - La Mancha - Diputación provincial de Toledo.

Bueno, P.; Barroso, R.; de Balbín, R. (2016): Entre vasijas y cerveza. El mundo funerario del interior peninsular en el III milenio cal. BC. Anejos a Cuadernos de Prehistoria y Arqueología de la Universidad Autónoma de Madrid 2: 49-58.

Bueno, P.; Barroso, R.; de Balbín, R. (2017): Redefining Ciempozuelos Bell-Beaker culture in Toledo?. Sinos e taças. Junto ao océano e mais longe. Aspectos da presença campaniforme na península ibérica (V. Gonçalves, ed.), UNIARQ, Lisboa: 324-341

Bueno, P.; Barroso, R.; de Balbín, R. (e.p.): Rojo de cinabrio en contextos megalíticos del Sur de Europa. Tradición megalítica y significado social del color en los hipogeos del interior peninsular. Workshop: El rojo en la antigüedad, Madrid. UNED.

Caillaud, R.; Lagnel, E. (1972) : Le cairn et le crématoire néolithiques de la Hoguette à Fontenay-le-Marmion (Calvados). Etude archéologique. Gallia Préhistoire, 15-1: 137-185.

Cámara, J.A.; Molina, F. (2009): El análisis de la ideología de emulación: El caso de El Argar. Cuadernos de Prehistoria y Arqueología de la Universidad de Granada, 19: 163-194.

Carvalho-Amaro, G. (2013): Bell Beaker ware from Estremadura, Portugal, and its likely influence on the appearance of Maritime Bell Beaker ware. Current researches on Bell Beakers Proceedings of the 15th International Bell Beaker Conference: From Atlantic to Ural, Pontevedra: 197-208.

Case, H, J. (1995): "Beakers: loosening a stereotype". Unbaked Urns of Rudely Shape (I.A. Kinnes; G. Varndell, eds.), Oxbow Monographs 5, Oxford: 55-67.

Clarke, D.L. (1970): Beaker Pottery of Great Britain and Ireland. Cambridge University Press, Cambridge.

Clarke, D.L. (1976): The Beaker network: social and economic models. Glockenbecher Symposion, Oberreid (J.N.Lanting; J. D. van der Waals, eds.), Bussum/Haarlem: 459-477. 
Colomer, L. (2005): Cerámica prehistórica y trabajo femenino en el Argar: una aproximación desde el estudio de la tecnología cerámica. Arqueología y género (Sánchez Romero, M. coord.), Universidad de Granada, Servicio de Publicaciones, Granada: 177-217.

De Miguel, M.P. (2006): Las mujeres en los contextos funerarios prehistóricos. Aportaciones desde la osteología. Las mujeres en la prehistoria, Museu de Prehistória de Valencia, Valencia: 91-104

Delibes, G. (2000): Cinabrio, huesos pintados en rojo y tumbas de ocre: ¿prácticas de embalsamamiento en la prehistoria?. Scripta in honorem a Enrique Llobregat Conesa, Diputación provincial de Alicante, Alicante: 223-236.

Díaz-del-Río, P.; Consuegra, S.; Audijeb, J.; Zapata, S.; Cambra, O.; González, A.; Waterman, A.; Thomas, J.; Peate, D.; Odriozola, C.; Villalobos, R.; Bueno, P.; Tykot, R.H. (2017): Un enterramiento colectivo en cueva del III milenio AC en el centro de la Península Ibérica: el Rebollosillo (Torrelaguna, Madrid). Trabajos de Prehistoria, 74 (1); 68-85. https://doi.org/10.3989/tp.2017.12184

Emslie, S.D.; Brasso, R.; Patterson, W.P.; Valera, A.C.; McKenzie, A.; Silva, A.M.; Gleason, J.D.; Blum, J.D. (2015): Chronic mercury exposure in Late Neolithic/Chalcolithic populations in Portugal from the cultural use of cinnabar. Scientific Reports | 5:14679 | DOI: 10.1038/srep14679.

Esparza, A.; Velasco, J.; Delibes, G. (2012): HUM 2005-00139: Planteamiento y primeros resultados de un proyecto de investigación sobre la muerte en Cogotas I. Cogotas I. Una cultura de la Edad del Bronce en la Península Ibérica (J.A. Rodríguez; J. Fernández Manzano eds.), Universidad de Valladolid, Valladolid: 259-320.

Estévez, F. 1966: La cueva sepulcral del Calvari d'Amposta (Montsià), Pyreane 2: 25-50.

Fabián, J. F. (2006): El IV y III milenio AC en el Valle del Amblés (Ávila). Arqueología en Castilla y León. Monografías 5, Junta de Castilla y León. Salamanca

Flores, R.; Garrido, R. (2014): Campaniforme y conflicto social: Evidencias del yacimiento de Humanejos (Parla, Madrid). Actas de las novenas Jornadas de Patrimonio Arqueológico en la Comunidad de Madrid, Madrid: 159-167.

García Puchol, O.; Gómez Pérez, O., Iborra, P. (2011): Sepulturas y depósitos especiales. La Vital (Gandia, Valencia). Vida y muerte en la desembocadura del Serpis durante el III y el I milenio a.C., (G. Pérez Jordá G.; J. Bernabeu; Y. Carrión; O. García-Puchol O.; LL. Molina; M. Gómez Puche, eds.), Serie de Trabajos Varios 113. Museu de Prehistòria de València, València: 83-96.

García Sanjuán, L.; Fernández Flores, A.; Díaz-Zorita, M. (2016): Montelirio. Valoración e interpretación de una tumba excepcional. Montelirio. Un gran monumento megalítico de la Edad del Cobre, (A. Fernández Flores; L. García Sanjuán; M. Díaz-Zorita, eds.), Arqueología monografías, Junta de Andalucía: 503-553.

Garrido, R. (2000): El campaniforme en la Meseta Central de la Península Ibérica (c.2500- 2000 AC). British Archaeological Reports International Series 892, Oxford

Garrido, R. (2014): Entre el consenso y la incertidumbre: perspectivas actuales en el estudio del fenómeno campaniforme. Actas de las novenas jornadas de Patrimonio Arqueológico en la Comunidad de Madrid, Madrid: 87-104.

Garrido, R.; Herrero, M. (2015): Children as potters: Apprenticeship Patterns from Bell Beaker Pottery of Copper Age Inner Iberia (Spain) (c. 2500-2000 cal BC), Children, Spaces and Identity (M. Sánchez Romero, E. Alarcón, G. Aranda, eds.), Oxbow books, Oxford: 40-58.

Gómez, J.L.; Blasco, C.; Trancho, G.; Rios, P.; Grueso, I.; Martínez, M.S. (2011): Los protagonistas.): Yacimientos calcolíticos con campaniforme de la región de Madrid: nuevos estudios. (C. Blasco; C. Liesau; P. Ríos eds.), Patrimonio arqueológico de Madrid 6, Universidad Autónoma de Madrid. UAM: 101-132.

González Marcén, P.; Montón, S.; Picazo, M. (2008): Towards an archaeology of maintenance activities. Engendering Social Dynamics: The Archaeology of Maintenance Activities, BAR International Series 1862: 3-8.

González Martín, A. (2008): Mitos y realidades en torno a la excavación, el tratamiento y el estudio de los restos arqueológicos no adultos. Nasciturus; infans, puerulus. Vobis mater terra. La muerte en la infancia, (S. Muriel; C. Olaria; F. Gusi, coords.), Diputación Provincial de Castellón, Castellón: 57-76.

González Ruibal, A. (2005): Etnoarqueología de la cerámica en el oeste de Etiopía. Trabajos de prehistoria, 62, 2: 41-66.

Guerra, E. (2006): Sobre la función y el significado de la cerámica campaniforme a la luz de los análisis de contenidos. Trabajos de Prehistoria, 62(1): 69-84. 
Heras, C.M; Cubas, M.; Bastida, A.B. (2014): Signos y símbolos en el registro funerario: Ajuares de la necrópolis calcolítica con campaniforme de "La Magdalena" I (Alcalá de Henares). Actas de las novenas jornadas de Patrimonio Arqueológico en la Comunidad de Madrid, Madrid: 187-198.

Hernando, A. (2008): Sexo, Género y Poder: Breve reflexión sobre algunos conceptos manejados en la Arqueología del Género. Complutum, 18: 167-174.

Higuero, A. (2015): Sesgos de género en la interpretación de los restos óseos humanos. Journal of Feminist, Gender and Women Studies, 2: 49-55.

Labaune, M. (2013): Bell Beaker metal and metallurgy in Western Europe. Current researches on Bell Beakers, Proceedings of the 15th International Bell Beaker Conference: From Atlantic to Ural, Pontevedra: $177-188$.

Lacalle, R., Guijo, J.M.,Cruz-Auñon, R. (2000): Estudio antropológico de cinco sepulturas prehistóricas de Castilleja de Guzmán (Sevilla). Actas do $3^{\circ}$ Congresso de Arqueologia Peninsular vol IX (V. O. Jorge, Coord.). ADECAP, Porto: 333-359.

Larsson, A.M. (2009): Breaking and making bodies and pots. Material and Ritual Practices in Sweden in the Third Millennium BC. Department of Archaeology and Ancient History. Aun 40. Uppsala.

Lemercier. O. 2011: Le guerrier dans l'Europe du 3er millénaire avant notre ère. L' arc et le poignard dans les sépultures individuelles campaniformes. L'armement et l'image du guerrier dans les sociétés anciennes. De l'objet à la tombe. Art \& Archéologie and Patrimoire: 121-165.

Liesau, C. (2016): Some prestige goods as evidence of interregional interactions in the funerary practices of the Bell Beaker groups of Central Iberia. Analysis of the Economic Supporting the Social Supremacy the Beaker Groups (E. Guerra; C. Liesau eds), Proceedings of the XVII UISPP World Congress, Burgos, Archaeopress publishing LTD: 69-93.

Liesau, C. (2017): Fauna in Living and Funerary Contexts of the 3rd Millennium BC in Central Iberia. Key Resources and Sociocultural Developments in the Iberian Chalcolithic, (M. Bartelheim; P. Bueno; Kunst, M. eds.), RessourcenKulturen 6, Universitätsbibliothek Tübingen: 107-128.

Liesau, C.; Blasco, C. (2012): Materias primas y objetos de prestigio en ajuares funerarios como testimonios de redes de intercambio en el Horizonte campaniforme. Cuadernos de Prehistoria y Arqueología, 37-38: 209-222.

Liesau, C.; Blasco, C.; Ríos, P.; Flores, R. (2015): La mujer en el registro funerario campaniforme y su reconocimiento social. Trabajos de Prehistoria 72:1: 105-125. https://doi.org/10.3989/tp.2015.12146

Lieverse, A.; Ivanovich, V.; Weber, A.W. (2015): Death by Twins: A Remarkable Case of Dystocic Childbirth in Early Neolithic Siberia. Antiquity, 89 (343): 23-38. https://doi.org/10.15184/aqy.2014.37

Linares, J.A.; Vera, J.C. (2015): La necrópolis del III milenio de El Seminario (Huelva). Organización espacial, contextos y prácticas funerarias. Death as Archaeology of Transition: Thoughts and Materials, BAR International Series 2708, Oxford: 275-290.

Lomba, J.; López, M.; Ramos, F.; Avilés, A. (2009): El enterramiento múltiple, calcolítico, de Camino del Molino (Caravaca, Murcia). Metodología y primeros resultados de un yacimiento excepcional. Trabajos de Prehistoria, 66, 2: 143-159.

López Padilla, J.A.; De Miguel, M.P.; Arnay, M.; Galindo, L.; Rodlán, C.; Murcia, S. (2012): Ocre y cinabrio en el registro funerario de El Argar. Trabajos de Prehistoria, 69(2): 273-292. https://doi.org/10.3989/ tp.2012.12092

Lull, V.; Mico, R.: Rihuete, C.; RISCH, R. (2016): Argaric Sociology: Sex and Death. Complutum 27(1): 37-62. http://dx.doi.org/10.5209/CMPL.53216

Makarowicz, P. (2015): Personal identity and social structure of Bell Beakers: The upper basins of the Oder and Vistula rivers. The Bell Beaker Transition in Europe: Mobility and local evolution during the 3rd millennium BC. (M.P. Prieto; L. Salanova, eds.), Oxbow books. Oxford \& Philadelphia: 15-27.

Malgosa, A.; Alesan, A.; Safont, S.; Ballbe, M.; Ayala, M.M. (2004): A Dystocic Childbirth in the Spanish Bronce Age. Internacional Journal of Osteoarchaeology, 14: 98-103. https://doi.org/10.1002/oa.714|

Mercadal, O.; Agustí,B. (2003): Estudi paleoantropològic. La Costa de Can Martorell (Dosrius, El Maresme), Laietania 14. Museo de Mataró- Secció Arqueológica: 75-115.

Montón-Subías, S. (2007): Interpreting archaeological continuities: an approach to transversal equiality in the Argaric Bronze Age of south-east Iberia. World Archaeology, 39 (2): 246-262. https://doi. org/10.1080/00438240701257721

Montón-Subías, S. (2010): Muerte e identidad femenina en el mundo argárico. Trabajos de prehistoria, 67(1): 119-137. https://doi.org/10.3989/tp.2010.10033 
Montón-Subías, S. (2014): Gender, Feminist, and Queer Archaeologies: Spanish Perspective. Encyclopedia of Global Archaeology (C. Smith ed), Nova York, Springer: 2981-2988.

Nava, A.; Coppa, A.; Coppola, D.; Mancini, L.; Dreossi, D.; Zanini, F.; Bernardini, F.; Tuniz, C.; Bondioli, L. (2017): Virtual histological assessment of the prenatal life history and age at death of the Upper Paleolithic fetus from Ostuni (Italy). Scientific Reports 2017 Aug 25;7(1):9427. doi: 10.1038/s41598017-09773-2.

Palomino, A.; Delibes, G.; Rojo, M. A.; Abarquero, F. J.; Moreno, M. A.; Negredo, M. J. (2006): El Turrumbero de la Cañada, Arquitectura megalítica al pie de la Sierra de Atapuerca (Burgos). Simbolismo, arte e espaços sagrados na pré-história da Península Ibérica, IV Congresso de Arqueología Peninsular, Faro, Universidade do Algarve: 143-56.

Perera, J.; Garrido, G.; Pérez, J. y Rojas, J.M. (2010): La excavación arqueológica en el yacimiento Las Mayores en Numancia de la Sagra (Toledo). Campaniforme y Bronce en la Comarca de la Sagra. Actas de las II Jornadas de arqueología de Castilla - La Mancha Vol. 1, Toledo CD.

Pérez Villa, A. (2015): Pautas funerarias y demográfica de la Edad del bronce en la cuenca media del Tajo. Bibliotheca Praehistorica Hispana 31, Madrid.

Rascón, J. (2017): Análisis de las diferencias sexuales en la morfología del esqueleto y de la distribución de caracteres de interés relacionados con el sexo. Estudio de dos series medievales de la Península Ibérica. Tesis doctoral UAM. Departamento de Biología.

Rice, P. M. (1999): Mujeres y producción cerámica en la Prehistoria. Arqueología y teoría feminista: estudios sobre mujeres y cultura material en arqueología, L. Colomer; P. González; S. Montón; M. Picazo, eds.), Icaria, Barcelona: 215-232.

Rojo, M.; Garrido, R.; García de Lagrán, I. (2008): Everyday routines special ritual events? Bell Beakers in domestic contexts of Inner Iberia. Bell Beaker in Everyday Life. Proceedings of the 10th Meeting Archéologies et gobelets, Florence-Siena-Villamora sul Clisi: 321-326.

Rojo, M.; Kunst, M.; Garrido, R.; García, I.; Morán, G. (2005): Un desafio a la eternidad: tumbas monumentales del Valle de Ambrona. Arqueología en Castilla y León 14, Valladolid.

Salanova, L. (2011): Chronologie et facteurs d'évolution des sépultures individuelles Campaniformes dans le nord de la France. Gallia Préhistoire, XLI: 125-142.

Sampedro, C.; Liesau, C. (1998): Los restos antropológicos. La Prehistoria madrileña en el Gabinete de Antigüedades de la Real Academia de la Historia (C. Blasco; J. Baena; C. Liesau eds.). Patrimonio Arqueológico del Bajo Jarama 3, Universidad Autónoma de Madrid. Madrid: 34-55.

Sánchez Romero, M. (2006): Maternidad y prehistoria: prácticas de reproducción, relación y socialización. Las mujeres en la prehistoria, Museu de Prehistória de Valencia, Valencia: 119-137

Sánchez Romero, M. (2008): Cuerpos de mujeres: la construcción de la identidad y su manifestación durante la Edad del Bronce. ARENAL, 15:1; 5-29.

Shennan, S.J. (1977): The appearance of the Bell Beaker assemblage in central Europe. Beakers in Britain and Europe: four studies. British Archaeological Reports, International Series, 26: 51-70.

Sherratt, A. (1987): Cups that Cheered. Bell Beakers of the Western Mediterranean. Definition, interpretation and data. The Oxford international Conference 1986. (W. H. Waldren; R.C. Kennard, eds.), British Archaeological Reports, Oxford 331: 81-114.

Sørensen, M.L.S (2000): Gender archaeology. Polity Press, Cambridge.

Soriano, I.; Martínez, P.; Labaune, M.; Cattin, F.; Oliart, C. (2016): 60 anys després de la Cova del Calvari (Amposta, Montsià). Revisió en curs i aportació de noves dades analítiques al Campaniforme del nordest de la Península Ibèrica. I Jornades d'Arqueologia de les Terres del L'Ebre, Tortosa, 105-116.

Thomas, J. (1991): Reading the Body: Beaker funerary practice in Britain. Sacred and Profane. Proceedings of a Conference on Archaeology, Ritual and Religion (P. Garwood; D. Jennings; R. Skeates; J. Toms, eds.), Oxford University Committee for Archaeology, Oxford: 33-42.

Turek, J. (2013): Age and Gender Identities in European Copper Age: An Anthropological Perspective. Indian Anthropologist, Vol. 43, 2: 73-86.

Vacca E.; Formicola V. ; Pesce Delfino V. ; Coppola D. (2012): I resti scheletrici umani delle sepolture paleolitiche di Grotta. Santa Maria d'Agnano - Ostuni (Brindisi). Il. Riparo di Agnano nel Paleolitico Superiore ( D. Coppola ed.). Università di Roma Tor Vergata: 201-364.

Valera, A.C. (2014): Bela Vista 5. Um recinto fo Final do $3^{\circ}$ Milénio a.n.e. (Mombeja, Beja). Era monográfica 2, Lisboa 
Vander Linden, M. (2006): Le phénomène campaniforme dans l'Europe du 3ème millénaire avant notre ère. Synthèse et nouvelles perspectives. British Archaeological Reports, International Series, 1470, Oxford.

Vazquez, A. (2009): Reflexión sobre el Campaniforme a partir de la evidencia funeraria de la cuenca del Tajo (España y Portugal). ARQUEOWEB 11.

Vergnaud, L. (2013): The Bell Beaker funeral group from Sierentz "Les Villas d'Aurèle" Current researches on Bell Beakers, Proceedings of the 15th International Bell Beaker Conference: From Atlantic to Ural, Pontevedra: 51-59

Willis, A.; Oxenham, M.F. (2011): A case of Maternal and Perinatal Death in Neolithic Southern Vietnam, c. 2100-1050 BCE. International Journal of Osteoarchaeology, 22, 6: 676-684. https://doi.org/10.1002/ oa. 1296

Zilhao, J. (2016): Beaker people without beaker pots: the Chalcolithic funerary context from the Galeria da Cisterna (Almonda karst system, Torres Novas, Portugal). Del neolític a l'edat del bronze en el Mediterrani occidental, Serie de Trabajos Varios 119, Valencia: 379-386. 